\title{
Threatened Native Trees in Guam: Short-term Seed Storage and Shade Conditions Influence Emergence and Growth of Seedlings
}

\author{
Thomas E. Marler ${ }^{1}$ and April Cascasan \\ Western Pacific Tropical Research Center, College of Natural and Applied \\ Sciences, University of Guam, UOG Station, Mangilao, GU 96923
}

\author{
John H. Lawrence \\ United States Department of Agriculture, Natural Resources Conservation
} Service, Mongmong, GU 96910

Additional index words. Elaeocarpus, plant propagation, recalcitrant seed, Serianthes, Tabernaemontana

\begin{abstract}
Seedling emergence and growth traits of three rare and threatened tree species in the Mariana Islands were studied within a range of incident light levels and up to 9 months of seed storage. Seedling emergence percentage and velocity were maximized in moderate shade for Elaeocarpus joga Merr., deep shade for Serianthes nelsonii Merr., and full sunlight for Tabernaemontana rotensis (Kaneh.) P.T. Li. Seedling height was increased by shade for $E$. joga and $S$. nelsonii. Height of $T$. rotensis seedlings was not influenced by incident light from $25 \%$ to $100 \%$. Nine months of seed storage at ambient temperature did not influence emergence percentage of $E$. joga or $S$. nelsonii seeds. In contrast, seeds of $T$. rotensis began declining in seedling emergence percentage between 2 and 3 months of storage, and seedling emergence was nil by 4 months. This study represents the first experimental approach to determining the influences of light and storage on seed and seedling behavior for any rare and threatened taxa from the Mariana Islands. Our findings that revealed highly contrasting responses among the species provide a valuable start to building the knowledge base needed to respond to formal recovery or conservation plans by defining horticultural protocols for managing a conservation nursery.
\end{abstract}

Managing cultivated plants of rare tree species presents challenges because inadequate species-specific horticultural knowledge is available, and seed collections are often highly regulated and limited. Decision makers and researchers recognize the need to effectively confront the data deficiency that is inherent to rare species research and management. Deciding how to allocate limited resources to achieve maximum conservation benefit within recovery plans, for example, cannot accurately proceed in the absence of species-specific research. Moreover, the value of each individual specimen in conservation research mandates the employment of the most accurate horticultural protocols. This restriction may hinder the inclusion of some treatments in traditional horticultural experimental approaches if death or compromised plant health is predicted to result from those treatments.

Received for publication 25 Feb. 2015. Accepted for publication 21 May 2015 .

Support provided by United States Department of Defense Agreements DAMD17-00-2-0021, FA524004-P-0099, and N40192-12-P-5006 to T.E.M. and administered by Andersen Air Force Base.

${ }^{1}$ To whom reprint requests should be addressed; e-mail tmarler@uguam.uog.edu.
These and other restrictions to effectual management of rare plant nurseries are magnified by the fact that the skill level required by horticulturists to maintain a specialized conservation nursery is highly dependent on the requirements of each taxon. An understanding of the species-specific requirements is needed to effectively manage human resources by assigning highly capable horticultural technicians to care for the most problematic species. Therefore, empirical research results are a prerequisite to managing this aspect of a conservation nursery.

Several tree species that are native to the Mariana Islands are characterized by limited regeneration potential and extensive habitat loss, and the need for formal conservation has become paramount. Elaeocarpus joga, $S$. nelsonii, and $T$. rotensis are three of these species. Informal information that was generated in the absence of scientific rigor is often available for propagation and nursery care of seedlings, even for rare species such as these. For example, several writings discuss anecdotal observations on $S$. nelsonii seed germination (Richardson and Marutani, 1997; USFWS, 1994) or E. joga germination (Ritter and Naugle, 1999). However, to date, we know of no published reports that used an experimental approach to accurately increase knowledge on the specifics of nursery protocols for any rare species in the Mariana Islands. Nurseries positioned to pursue recovery plans or respond to conservation efforts are hindered by this lack of information.

We have conducted conservation projects on these three species, which included nursery research. The initial objective herein was to determine the influence of a wide range of ambient light exclusion levels on seedling emergence and early seedling growth traits of these three species. The secondary objective was to determine the influence of 9 months of seed storage on seedling emergence percentage. The results will inform management decisions for conservation nurseries.

\section{Materials and Methods}

Separate experiments were conducted for each of the species, and individual shade structures were constructed for each replication within each of the experiments. Individual Quonset-shaped structures were constructed for each replication and oriented such that the solar beam was about perpendicular to the shade fabric throughout the diurnal period. The 12.7-mm diameter polyvinyl chloride pipe frames were affixed directly to the benches and then commercial shade fabric with varied percentage light reduction was installed on the framing. The reduction in photosynthetically active radiation was measured directly with a quantum sensor (Model SKP200; Skye Instruments, Ltd., Powys, UK) in each shade structure at midday on clear days. The influence of light level on medium temperature was also measured directly with a J-type thermocouple positioned at $0.5 \mathrm{~cm}$ depth (Comark DT33, Beaverton, OR). Measurements were made hourly throughout diurnal periods on clear days during the germination phase of each experiment. All experiments were conducted at the University of Guam campus on raised benches, and replications were arranged in blocks with one shade structure per treatment in each block. Benches were positioned east to west, and blocks were arranged east to west on the benches.

For each experiment, a replication for the emergence data was defined as one container with five seeds. The seeds were planted $0.5 \mathrm{~cm}$ deep in $60 \%$ peat: $40 \%$ perlite medium in $0.625-\mathrm{L}$ containers, and containers were irrigated daily as needed. Each of the emerged seedlings was transplanted to an individual 2.6-L container after two to three sets of true leaves had developed above the cotyledons. The seedling containers from each replication were maintained in the same shade structure, and collectively considered one replication. Beginning on the day that the seedlings were transplanted, containers were fertilized weekly with $25 \mathrm{~mL}$ of complete fertilizer solution (Miracle-Gro; The Scotts Co., Marysville, $\mathrm{OH}$ ) providing $7.5 \mathrm{~mm} \mathrm{~N}$. The hypocotyl length was measured for each seedling just before the transplanting procedure as the height of the cotyledon scars 
above the medium surface, then seedling height was monitored weekly until the replications within at least one shade level averaged $30 \mathrm{~cm}$ in height. At that stage, the height of every seedling in the experiment was measured, and the experiment was ended.

Species treatments. Incident light levels were $25 \%, 50 \%, 75 \%$, or $100 \%$ transmission for $E$. joga, and there were 10 replications. Freshly fallen fruits were collected from four E. joga trees in northern Guam on 15-16 Jan. 2001. Pericarp was cleaned from the fruits on the day of harvest then the exposed endocarps were allowed to dry at ambient temperatures in shade. Our preliminary research and anecdotal reports (e.g., Ritter and Naugle, 1999) indicated this was required for efficient removal of seeds from the endocarp, that germination was inhibited by retention of the endocarp, and that no further treatment of extracted seeds was required to improve germination. All of the fruits were combined into one homogenized batch. The endocarp for each fruit was cracked, and seeds were removed on 4-5 Feb. 2001. The seeds were planted on 5 Feb. 2001.

Incident light levels were $25 \%, 47 \%$, $65 \%$, or $100 \%$ for $T$. rotensis, and there were six replications. We followed a mast flowering event among the $T$. rotensis trees in northern Guam that resulted from the passage of Tropical Depression 18W on 30 Sep. 2009. The resulting fruits were harvested on 8-9 Feb. 2010 from three groves of trees. Seeds were extracted, cleaned, and combined into a homogenized batch. Our preliminary research indicated that seed scarification was not required to improve germination, but imbibing seeds and changing the water periodically for $12 \mathrm{~h}$ improved germination. The experiment was initiated on 10 Feb. 2010 with $12 \mathrm{~h}$ of soaking in municipal water, with a change in water every $2 \mathrm{~h}$.

Incident light levels were $25 \%, 47 \%$, $65 \%$, or $100 \%$ transmission for S. nelsonii, and there were six replications. All S. nelsonii seeds were collected under Endangered Species Act Recovery Permit TE-84876A-0 from the only known remaining living tree on Guam. Repeated litterfall collections ensured that each successive collection date was composed of freshly fallen seeds and fruits. Seeds collected in Nov. 2012 were used to plant replications 1 and 2 on 4 Apr. 2013. Seeds collected in Jan. 2013 were used to plant replication 3 on 13 May 2013 and replication 4 on 31 May 2013. Seeds collected in Feb. 2013 were used to plant replication 5 on 15 June 2013. Seeds collected in Mar. 2013 were used to plant replication 6 on 20 July 2013. Anecdotal published reports and our preliminary research indicated that seedcoat scarification was required for effective germination. Following scarification, we attempted imbibing durations of $1,2,4,8$, or $10 \mathrm{~h}$, and only $1-2 \mathrm{~h}$ elicited adequate germination. For this study, each seed was scarified by scratching one side on 100-grit sandpaper until the cotyledon tissue could be seen, then $1 \mathrm{~h}$ of imbibing in municipal water preceded planting.
Response variables. The number of emerged seedlings in each container was recorded daily for the duration of the emergence phase of each study. The minimum time to emergence was defined as the number of days from sowing to emergence of the first seedling in each replication. Mean time for emergence was the mean number of days for all emerged seedlings within a replication. Final emergence was defined as the cumulative number of seedlings that emerged as a percentage of seeds planted. The emergence velocity index was a modification of the germination test defined by Woodstock (1976), and was defined as N1/1 + N2/2 + $\mathrm{N} 3 / 3$, etc. where $\mathrm{N} 1, \mathrm{~N} 2, \mathrm{~N} 3$, etc. were the number of newly emerged seedlings on days $1,2,3$, etc. following the date of sowing. This value integrates every seedling within each replication, and its value is greater if more seeds emerge in the fewest number of days.

Data were subjected to analysis of variance (ANOVA) as a randomized complete block design using SAS Version 9.1 (SAS Institute, Inc., Cary, NC) to determine effects of incident light on emergence and seedling growth traits. Percentage emergence data were arcsine transformed before analysis. The other response variables met all assumptions. Linear and/or quadratic regression models significantly described the influence of incident light on every response variable that initially exhibited differences among the means. Percentage emergence data were back-transformed for graphical presentation.

Storage. The influence of up to 9 months of seed storage on seedling emergence percentage was initiated on the same day of planting the original experiments for $E$. joga and $T$. rotensis. Seeds were stored in paper bags in an outdoor laboratory with ambient temperature and humidity, which were recorded by hygrothermograph. High and low storage temperatures for $E$. joga seeds were 30.1 and $25.2^{\circ} \mathrm{C}$. Relative humidity was $69 \%$ for mean daily lows and $91 \%$ for mean daily highs. High and low storage temperatures for $S$. nelsonii were 29.8 and $24.7^{\circ} \mathrm{C}$. Relative humidity was $66 \%$ for mean daily lows and $91 \%$ for mean daily highs. High and low temperatures for the months that $T$. rotensis seeds exhibited emergence were 29.6 and $24.6{ }^{\circ} \mathrm{C}$, whereas high and low relative humidity during the same period was $89 \%$ and $69 \%$.

For E. joga, the seeds were stored inside intact endocarps until each subsequent planting date. Following each successive month of storage up to 9 months, 30 seeds were removed from the seed batch and planted as six replications in accordance with the methods for the original experiment. Full sun conditions were used for $T$. rotensis, and $50 \%$ shade was used for E. joga. For $S$. nelsonii, seeds were harvested on 20 June 2013 and 3 July 2013 and mixed into one comingled batch. Fifteen seeds were removed from the batch and planted as three replications on 5 July 2013, and seedling emergence was quantified under $25 \%$ ambient light transmission. The procedure was repeated at 3,6 , and 9 months due to limited number of available seeds. The effects of storage time on emergence percentage were determined by ANOVA following arcsine transformation.

\section{Results}

Seedling emergence percentage for $E$. joga was $\approx 60 \%$ under full sun conditions and $90 \%$ to $95 \%$ under shaded conditions (Fig. 1, $P \leq 0.0001$ ). The influence of incident light on emergence fit a quadratic model. A linear decline in seedling emergence percentage for $S$. nelsonii occurred with $85 \%$ emergence under the lowest light level and $10 \%$ emergence under full sun $(P \leq 0.0001)$. A linear increase in seedling emergence percentage for $T$. rotensis occurred with $60 \%$ emergence under the lowest light level and $90 \%$ emergence under full sun $(P=0.0031)$.

Speed of initial seedling emergence was not influenced by incident light level for $E$. joga $(P=0.4683)$, and ranged from 17.5 to $18.8 \mathrm{~d}$ (Table 1). In contrast, mean speed of seedling emergence was influenced by incident light ( $P \leq 0.0001)$, and was most rapid in moderate shade and slowest at $25 \%$ incident light. Initial seedling emergence for $S$. nelsonii was $5.8 \mathrm{~d}$ and was not influenced by incident light level $(P=0.8163)$. Similarly, mean number of days for emergence was $6.6 \mathrm{~d}$ and was not influenced by incident light $(P=0.0763)$. Speed of initial seedling emergence was influenced by incident light level for $T$. rotensis $(P=0.0002)$, and was most rapid in the lowest incident light levels (Table 1). Mean speed of seedling emergence was also influenced by incident light $(P=$ $0.0004)$, and was most rapid in the highest incident light levels.

Velocity index of E. joga seedling emergence was influenced by incident light $(P \leq$ 0.0001 ), and exhibited a quadratic relationship with the most rapid index occurring under moderate incident light levels (Fig. 2). Velocity index of $S$. nelsonii seedling emergence was highly contrasting among the incident light levels $(P=0.0002)$, with a steep linear decline in the index with increased light. Velocity index of $T$. rotensis seedling emergence was also influenced by incident light levels $(P=0.0037)$. Variation among replications within each treatment was minimal, which enabled the fitting of a significant linear model with positive slope.

Incident light level influenced hypocotyl length of $E$. joga $(P \leq 0.0001), S$. nelsonii $(P=0.0008)$, and $T$. rotensis $(P \leq 0.0001)$, with a linear decline in hypocotyl length occurring with increased incident light for every species (Fig. 3). Elaeocarpus joga seedlings growing under full sun conditions exhibited about $75 \%$ mortality by week 6 , but every replication had at least one seedling remaining alive for the duration of the experiment. The seedlings under $25 \%$ incident light reached $30 \mathrm{~cm}$ in height following 16 weeks of growth (Fig. 4). At that time, the differences among the light levels were highly contrasting $(P \leq 0.0001)$, with seedlings under $75 \%$ or 


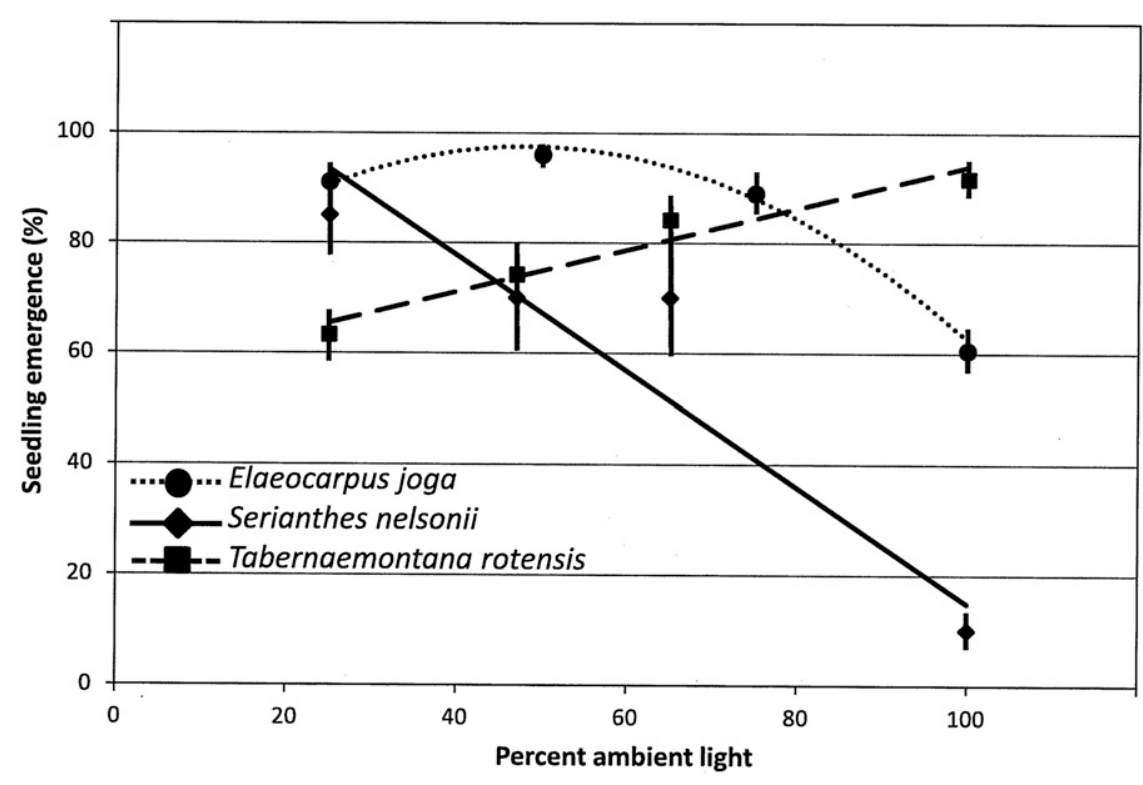

Fig. 1. Seedling emergence percentage of Elaeocarpus joga $\left(y=67.50+1.25 x-0.013 x^{2}, P \leq 0.0001, r^{2}=\right.$ $0.62)$, Serianthes nelsonii $\left(y=119.61-1.05 x, P \leq 0.0001, r^{2}=0.67\right)$, and Tabernaemontana rotensis $\left(y=55.91+0.38 x, P \leq 0.0001, r^{2}=0.51\right)$ as influenced by incident light. Mean \pm SE.

Table 1. Speed of seedling emergence of Elaeocarpus joga $(\mathrm{n}=10)$, Serianthes nelsonii $(\mathrm{n}=6)$, and Tabernaemontana rotensis $(\mathrm{n}=6)$ seedlings sown under four incident light levels. First emergence was day in which the first seedling in a replication emerged. Mean emergence was mean number of days for all emerged seedlings within a replication. Means $\pm \mathrm{SE}$.

\begin{tabular}{lcc}
\hline Incident light level & First emergence $(\mathrm{d})$ & Mean emergence $(\mathrm{d})$ \\
\hline $25 \%$ & Elaeocarpus joga & $30.0 \pm 0.7$ \\
$50 \%$ & $18.8 \pm 0.2$ & $21.0 \pm 0.4$ \\
$75 \%$ & $17.5 \pm 0.2$ & $21.4 \pm 0.3$ \\
$100 \%$ & $18.8 \pm 0.2$ & $24.4 \pm 0.5$ \\
Significance & $18.7 \pm 0.4$ & $\mathrm{Q}^{* *}$ \\
& $\mathrm{NS}$ & $6.7 \pm 0.2$ \\
$25 \%$ & Serianthes nelsonii & $6.3 \pm 0.3$ \\
$47 \%$ & $5.8 \pm 0.2$ & $7.4 \pm 1.4$ \\
$65 \%$ & $5.3 \pm 0.7$ & $6.0 \pm 0.0$ \\
$100 \%$ & $6.3 \pm 1.4$ & $\mathrm{NS}$ \\
Significance & $6.0 \pm 0.0$ & $43.8 \pm 1.2$ \\
& $\mathrm{NS}$ & $40.2 \pm 1.8$ \\
$25 \%$ & Tabernaemontana rotensis & $36.5 \pm 0.8$ \\
$65 \%$ & $28.3 \pm 0.2$ & $35.8 \pm 0.6$ \\
$100 \%$ & $28.7 \pm 0.2$ & $\mathrm{~L} * *$ \\
Significance & $33.3 \pm 1.4$ & $\mathrm{~L}$ \\
\hline
\end{tabular}

NS, ${ }^{*}$ Nonsignificant or $P \leq 0.01$, respectively, for linear (L) or quadratic (Q) models.

$100 \%$ incident light exhibiting heights of about $13 \mathrm{~cm}$. The E. joga data conformed to a quadratic response model. Serianthes nelsonii seedlings growing under full sun exhibited rapid death, with $100 \%$ mortality in less than 2 weeks following emergence. Seedlings under all three shade treatments also exhibited seedling mortality, with about $40 \%$ of the seedlings dying within 3 weeks of emergence. Remaining seedlings under $25 \%$ incident light reached $30 \mathrm{~cm}$ following only 12 weeks of growth. At that time, height of the seedlings that remained alive under the three shade levels were significantly influenced by light $(P=0.0017)$, and exhibited a linear decline in height with increased incident light level. Tabernaemontana rotensis seedlings required 26 weeks to reach $30 \mathrm{~cm}$ in height, and incident light level did not influence seedling height at that stage $(P=0.9399)$.
Container medium temperature at 0.5 $\mathrm{cm}$ depth was strongly influenced by ambient light transmission during the diurnal period (data not shown). The $25 \%$ transmission treatment level generated container medium temperatures that were $2-3{ }^{\circ} \mathrm{C}$ above ambient temperature. The $47 \%$ to $50 \%$ transmission treatment levels generated medium temperatures that were $3-4{ }^{\circ} \mathrm{C}$ above ambient temperature. The $65 \%$ to $75 \%$ transmission treatment levels contained replications with medium temperature that was $8-10{ }^{\circ} \mathrm{C}$ above ambient temperature. Full sun conditions generated container medium temperatures that were $12-14{ }^{\circ} \mathrm{C}$ above ambient temperature. On a typical clear day, the replications in the full sun treatment contained medium in the vicinity of the seeds exhibiting temperatures of $42-44{ }^{\circ} \mathrm{C}$.
Storage for 9 months did not influence $E$. joga emergence percentage $(P=0.9707)$, which remained above $95 \%$ for the duration of the study (Fig. 5). Storage for 9 months did not influence $S$. nelsonii emergence percentage $(P=0.8417)$, and emergence remained about $85 \%$ for the duration of the study (Fig. 5). Storage exhibited a strong influence on seedling emergence of $T$. rotensis $(P \leq 0.0001)$. Emergence remained above $91 \%$ for 2 months, declined to about $60 \%$ in the $3 \mathrm{rd}$ month, and was nil by the 4 th month (Fig. 5).

\section{Discussion}

Germination and early seedling growth studies on rare taxa are critical for prescribing optimal nursery protocols to produce plants for use in urban managed forests, conservation plantings, or reintroduction into natural areas for species recovery efforts. For these reasons, developing horticultural skills based on experimental results can provide opportunities to improve conservation of rare species (Pritchard et al., 2014). This report is the first to convey experimental results that describe the influences of light and storage on seed and seedling behavior for any rare and threatened taxa from the Mariana Islands. We selected the $30 \mathrm{~cm}$ stem height as the termination of the experiments because our collective experiences indicate seedling mortality ceases after the seedlings achieve some age and size, and we have not recorded any mortality in the nursery after the seedlings have achieved this height.

This detailed assessment of a range of shade conditions revealed highly contrasting performance among the model species. Elaeocarpus joga seeds required up to 1 month to emerge, required shaded conditions for adequate emergence and early seedling establishment, and reached $30 \mathrm{~cm}$ in height after about 16 weeks. High light exposure killed about $75 \%$ of the seedlings that emerged with no shade protection. Tabernaemontana rotensis seeds required up to $45 \mathrm{~d}$ to emerge, required full sun exposure for the best seedling emergence percentage and speed, and reached $30 \mathrm{~cm}$ in height after about 26 weeks. Serianthes nelsonii seedlings were the most difficult to manage despite the seedling emergence speed of less than 1 week. Full sun was devastating to emergence percentage and killed every seedling that did emerge. No observable causal mechanism could be identified for the $40 \%$ seedling mortality that occurred in every shade level. However, the seedlings that did survive the initial pulse of mortality exhibited rapid growth by reaching $30 \mathrm{~cm}$ in height in about 12 weeks.

These results are informative for managing human resources in conservation nurseries. More specialized horticultural skills may be required for the initial phases of $E$. joga and $T$. rotensis seedling production, as adequate but not excessive water content in the container medium is needed for the lengthy germination and emergence stages. Once established, growing out the seedlings 


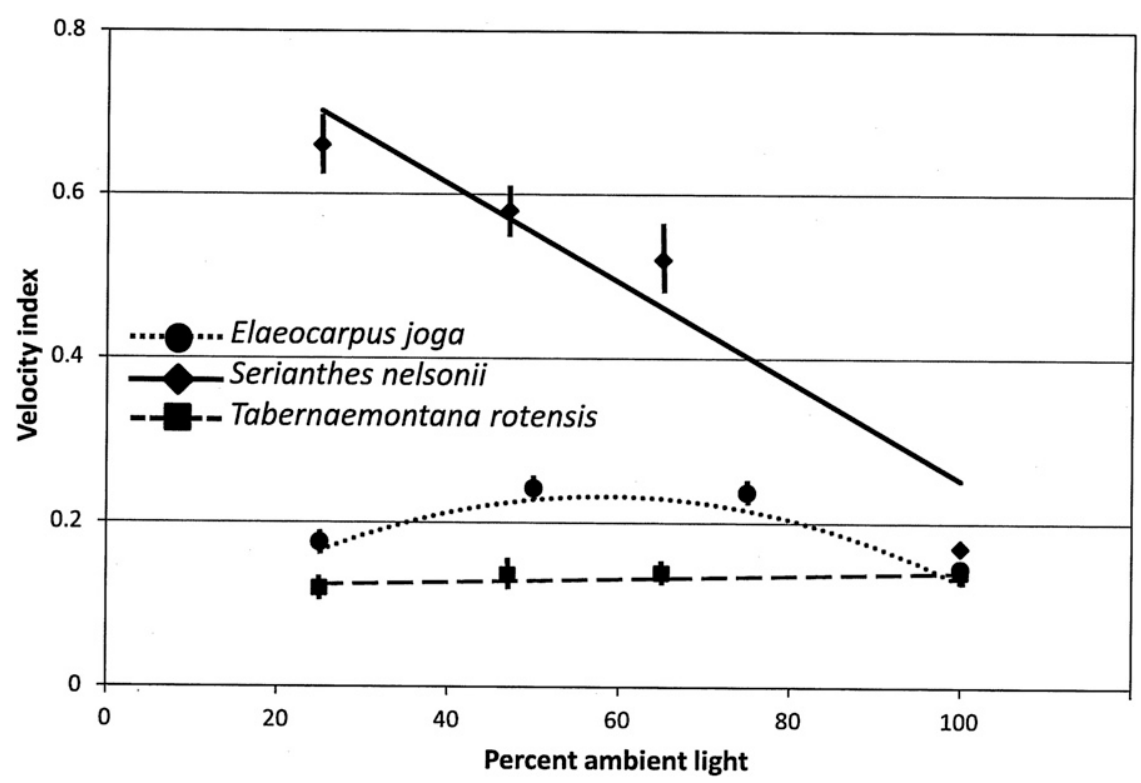

Fig. 2. Seedling emergence velocity index of Elaeocarpus joga $\left(y=0.028+0.007 x-0.00006 x^{2}, P \leq\right.$ $\left.0.0001, r^{2}=0.87\right)$, Serianthes nelsonii $\left(y=0.852-0.006 x, P=0.0033, r^{2}=0.53\right)$, and Tabernaemontana rotensis (nonsignificant) as influenced by incident light. Mean $\pm \mathrm{SE}$.

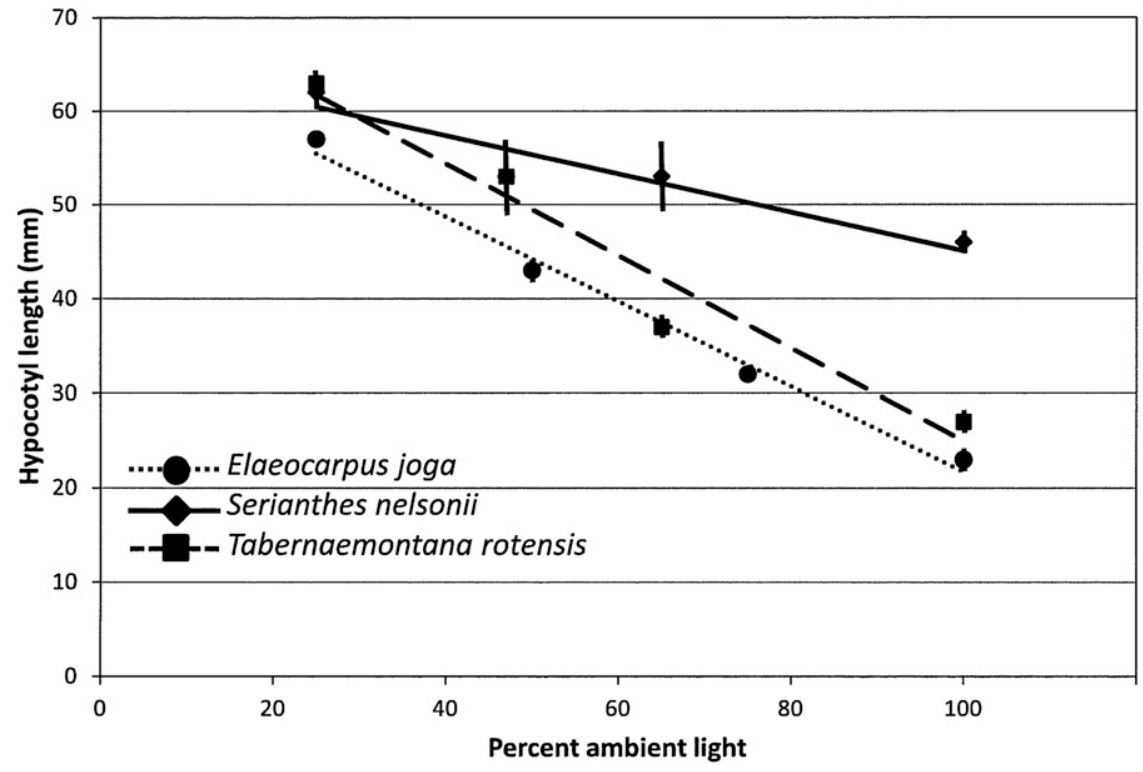

Fig. 3. Hypocotyl length of Elaeocarpus joga $\left(y=66.70-0.45 x, P \leq 0.0001, r^{2}=0.91\right)$, Serianthes nelsonii $\left(y=65.58-0.21 x, P=0.0062, r^{2}=0.43\right)$, and Tabernaemontana rotensis $(y=73.96-0.49 x$, $P \leq 0.0001, r^{2}=0.89$ ) seedlings as influenced by incident light. Mean $\pm \mathrm{SE}$.

of these two species may not require highly specialized skills if shade is provided for the E. joga stock. The results of this study and the many unsuccessful historical attempts to grow $S$. nelsonii plants in container nurseries (Wiles et al., 1996) indicate highly specialized horticultural knowledge and skills are needed to manage seedling production of this species. Considering the critically endangered status of this endemic species, the extremely limited availability of seeds, and the lack of historical response to the call for formal research to improve propagation techniques (Wiles et al., 1996), these results indicate recovery permit holders should be restricted to individuals with formal horticulture or silviculture degrees. This assertion is further supported by the historical failures in outplanting success when transplants have been available on occasion.

Exploiting an ability to store seeds of rare trees is crucial for increasing options for conservation nursery management decisions. Determining viability of seeds following dry storage in ambient conditions is a useful start to understanding longevity, inhibitors, and after-ripening traits (FinchSavage and Leubner-Metzger, 2006; Mayer and Poljakoff-Mayber, 1982; Priestley, 1986). Tabernaemontana rotensis seeds appeared to be recalcitrant based on these results, with a decline in seedling emergence after only 2 months of seed storage. However, further studies are needed to determine if the rapid loss of seedling emergence is truly a loss of viability or is the initiation of a delayed dormancy mechanism. Until this has been accomplished, conservation organizations should adhere to the planting of fresh seeds of this species to ensure adequate germination is achieved. Seeds of the other species exhibited more orthodox traits, with no decline in germination performance within the storage time limits of this study. Continued research may focus on controlled drying of seeds to various degrees before storage and storage conditions defined by a range of temperatures. Continued research for E. joga could also include storage of extracted seeds vs. storage of seeds in unopened endocarps.

The species in this report are all rare, declining in incidence, regionally endemic, and not adequately regenerating in the forests. They are also ecologically and culturally important. However, the official status and relative level of formal conservation endeavors differ among the species. Serianthes nelsonii is the most endangered, was extremely rare as early as the initial written publication on the species (Merrill, 1919), and is represented by a few mature trees on Guam and Rota. The species was formally listed by the U.S. Fish and Wildlife Services in 1987 (USFWS, 1987), and a formal recovery plan was published 6 years later (USFWS, 1994). The species was red listed as critically endangered by the International Union for Conservation of Nature and Natural Resources in 1998 (Wiles, 1998). Tabernaemontana rotensis is currently proposed for listing by the USFWS (Ashe, 2014). With an endemic range of Guam and Rota, the attractive tree has horticultural appeal regardless of its national or international conservation status. Elaeocarpus joga has an endemic range from the Mariana Islands and Palau, is heavily exploited by native fauna and epiphytes, and a lack of regeneration has been documented for several decades (Raulerson and Rinehart, 1991; Ritter and Naugle, 1999; Stone, 1970; Vogt and Williams, 2004). Intact endocarps of members of this genus provide the resource for rudraksha, which carries myriad medicinal and spiritual symbolisms in Hinduism and Buddhism (Seetha, 2008). Another of the interesting horticultural traits of the genus is the iridescent blue fruits, with ultrastructural light refraction generating the blue appearance (Lee, 1991).

Conservation nurseries that specialize in rare and threatened plant species generally work with numerous taxa. Simplifying horticultural management decisions such as constructing a homogeneous shaded structure for the entire nursery operation would be advantageous. No single level of shade emerged as optimal for all three of the taxa we studied. However, incident light in the range of 50\% to $75 \%$ of ambient light would be adequate for $E$. joga and T. rotensis in a single nursery setting. The variation in performance among 


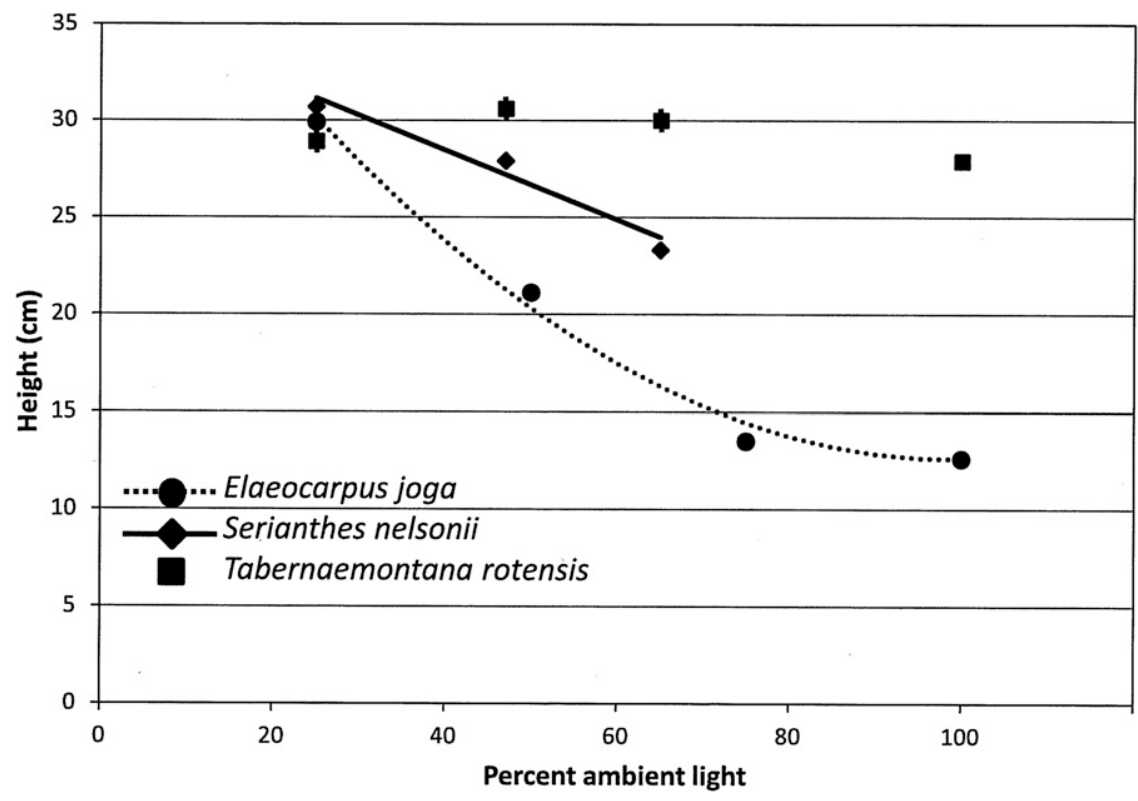

Fig. 4. Plant height of Elaeocarpus joga following 16 weeks $\left(y=43.99-0.63 x+0.032 x^{2}, P=0.0002, r^{2}=\right.$ $0.84)$, Serianthes nelsonii following 12 weeks $\left(y=35.65-0.18 x, P=0.0415, r^{2}=0.35\right)$, and Tabernaemontana rotensis following 26 weeks of growth (nonsignificant) as influenced by incident light. Serianthes nelsonii seedlings under 100\% light exhibited 100\% mortality. Mean \pm SE.

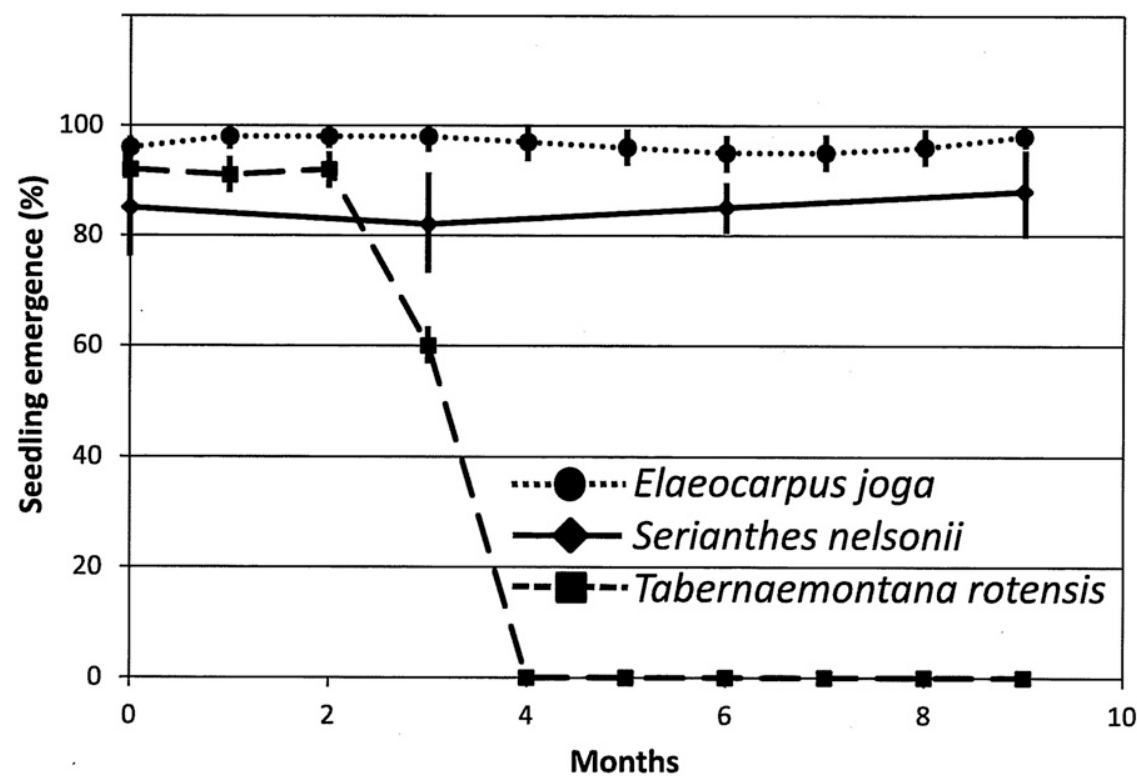

Fig. 5. Seedling emergence percentage of Elaeocarpus joga, Serianthes nelsonii, and Tabernaemontana rotensis as influenced by dry storage of seeds (months). Mean \pm SE.

the species was greatest for full sun conditions. Tabernaemontana rotensis seedling production would benefit from full sun conditions if proper care is provided, E. joga seedling production success would be inhibited under full sun conditions, and $S$. nelsonii seedling production would fail in a full sun nursery setting. The limited seedling emergence and subsequent seedling mortality in full sun conditions for $S$. nelsonii and E. joga may be a direct consequence of excessive general light load, a direct consequence of excessive ultraviolet exposure, or an indirect consequence of excessive temperatures
Our results indicate that some of the Guam seeds produce vigorous seedlings, with healthy seedlings reaching a height of $30 \mathrm{~cm}$ in only 12 weeks. However, we did record a high percentage of mortality for very young seedlings. We noted no pathogens, insects, or other obvious reasons for the rapid seedling mortality, indicating the behavior may indeed be a consequence of inbreeding. Initial testing of this possibility could be conducted with a properly paired experimental comparison of young seedling performance from Rota stock, where $S$. nelsonii trees are clustered and potentially outcross, with that from Guam stock, where a single tree is the maternal and paternal parent of every seed.

In preparation for these studies, we searched the literature on closely related species to access information that would aid in designing experiments. The number of reports was substantial, but experimental results on seed storage or light level during germination were lacking. Congeneric taxa of all three species in this study may be the target of conservation and restoration actions within their native range. Therefore, the results of our study may serve to aid in designing experiments with these other Elaeocarpus, Serianthes, and Tabernaemontana species.

This study exemplifies the importance of straightforward and uncomplicated horticulture research when no publications exist to inform decisions. These three species occupy the same forested habitats in their native range, and nursery managers may be tempted to assume the horticultural needs for germination and early seedling growth may be similar. In contrast, most response variables were highly contrasting among the taxa. For example, seedling emergence percentage of $E$. joga was greatest in moderate shade, of $S$. nelsonii was greatest in the most shaded conditions, and of $T$. rotensis was greatest in full sun conditions.

The remaining specimens of these and other rare endemic species are vestiges of Guam's ecosystems of the past. A concerted effort to study the ecology and horticulture of the remaining trees is imperative, as the current collective nescience on the requirements of the species was evitable if past formal projects had used appropriate experimental approaches. We suggest a shift to fund more direct research is needed to move beyond hearsay and anecdotes, and if ongoing funding efforts continue to focus on applied conservation this will vitiate future successes in collective conservation efforts (Marler and Lindström, 2014). Urgency is also underscored by ongoing destabilizing synergisms between climate change and island biology (Marler, 2014) and habitat loss and fragmentation due to enduring expansion of military operations (Marler and Moore, 2011).

In summary, conservation organizations and nurseries poised to pursue recovery plans or respond to calls for conservation are hindered by the general lack of information on how to handle seeds and seedlings. No 
empirical studies to date have been published for understanding the behaviors of the in situ seed bank, how to store collected seeds, or how to approach propagation protocols. Our results provide benchmark details for germination and early seedling growth of three rare endemic species, and help decision making move toward more effective conservation efforts.

\section{Literature Cited}

Ashe, D.M. 2014. Proposed endangered status for 21 species and proposed threatened status for 2 species in Guam and the Commonwealth of the Northern Mariana Islands. Fed. Regist. 79 (190):59364-59413.

Finch-Savage, W.E. and G. Leubner-Metzger. 2006. Seed dormancy and the control of germination. New Phytol. 171:501-523.

Lee, D.W. 1991. Ultrastructural basis and function of iridescent blue color of fruits in Elaeocarpus. Nature 349:260-262.

Marler, T.E. 2014. Pacific island tropical cyclones are more frequent and globally relevant, yet less studied. Frontiers in Environmental Science $2: 42$.

Marler, T.E. and A.J. Lindström. 2014. The value of research to selling the conservation of threat- ened species: The case of Cycas micronesica. J. Threatened Taxa 6:6523-6528.

Marler, T.E. and A. Moore. 2011. Military threats to terrestrial resources not restricted to wartime: A case study from Guam. J. Environmental Science \& Engineering 5:1198-1214.

Mayer, A.M. and A. Poljakoff-Mayber. 1982. The germination of seeds. 3rd ed. Pergamon Press, New York, NY.

Merrill, E.D. 1919. Additions to the flora of Guam. Philipp. J. Sci. 15:539-544.

Priestley, D.A. 1986. Seed aging: Implications for seed storage and persistence in the soil. Cornell Univ. Press, Ithaca, NY.

Pritchard, H.W., J.F. Moat, J.B.S. Ferraz, T.R. Marks, J.L.C. Camargo, J. Nadarajan, and I.D.K. Ferraz. 2014. Innovative approaches to the preservation of forest trees. For. Ecol. Mgt. 333:88-98.

Raulerson, L. and A. Rinehart. 1991. Trees and shrubs of the Northern Mariana Islands. Coastal Resources Management. Saipan, Commonwealth of the Northern Mariana Islands.

Richardson, J. and M. Marutani. 1997. Effect of pre-treatments on seed germination of Serianthes nelsonii Merrill (Fabaceae). Micronesica 30:439-440.

Ritter, M.W. and C.M. Naugle. 1999. Population characteristics, germination and proposed management of Elaeocarpus joga Merr. on Guam: A regionally endemic tree. Micronesica 31:275-281.
Seetha, K.N. 2008. Power of Rudraksha. 4th ed. Jaico Publishing House, Mumbai, India.

Stone, B.C. 1970. The flora of Guam. Micronesica 6:1-659.

United States Fish and Wildlife Service. 1987. Endangered and threatened wildlife and plants; determination of endangered status for Serianthes nelsonii Merr. (Hayun Lagu or Tronkon Guafi). Fed. Regist. 52(32):49074910.

United States Fish and Wildlife Services. 1994. Recovery plan for Serianthes nelsonii. U.S. Fish and Wildlife Service, Portland, Oregon. 28 May 2015. <http://www.fws.gov/ pacificislands/recoveryplans.html $>$.

Vogt, S.R. and L.L. Williams. 2004. Common flora and fauna of the Mariana Islands. Williams and Vogt. Saipan, Northern Mariana Islands.

Wiles, G. 1998. Serianthes nelsonii. The IUCN red list of threatened species. Version 2014.3. 28 May 2015. <http://www.iucnredlist.org>.

Wiles, G.J., I.H. Schreiner, D. Nafus, L.K. Jurgensen, and J.C. Manglona. 1996. The status, biology, and conservation of Serianthes nelsonii (Fabaceae), an endangered Micronesian tree. Biol. Conserv. 76:229-239.

Woodstock, L.W. 1976. Seed vigour testing handbook. Assoc. Official Seed Analysis of America Newsletter 50 